\title{
Associations among dairy cow body condition and welfare-associated behavioral traits
}

\author{
L. R. Matthews, ${ }^{\star 1}$ C. Cameron, ${ }^{\star}$ A. J. Sheahan, $†$ E. S. Kolver, $†$ and J. R. Roche† \\ ${ }^{*}$ AgResearch, PB 3123, 3204 Hamilton, New Zealand \\ †Dairy NZ Ltd., Newstead, 3286 Hamilton, New Zealand
}

\begin{abstract}
Some evidence exists that cow body condition score (BCS) is associated with risks to animal health, and that higher BCS in extensively kept animals provides a buffer against cold conditions or other adverse weather events. Not surprisingly, measures of BCS feature in dairy cattle welfare assessment protocols. However, the degree to which BCS predicts welfare state, particularly in relation to the level of "hunger" experienced, is not well researched. The aim of this study was to examine associations between naturally arising variations in BCS in dairy cattle and time spent engaged in activities used as proxy indicators of hunger. Holstein-Friesian cows (n $=113$ ) of either North American or New Zealand ancestry were allocated to 1 of 3 levels of concentrate-feed supplementation $(0,3$, or $6 \mathrm{~kg}$ of dry matter/d) and also offered pasture in excess of requirements. Body condition score (1 to 10 scale), pasture dry matter intake (DMI), and time budgets for grazing, ruminating, standing, and lying were recorded during early, mid, and late lactation. Body condition score varied over a wide range (2.5 to 8.5 ) and, within genetic strain and supplementation level, was inversely associated with pasture DMI, rate of DMI, and the proportions of time spent grazing and ruminating. In comparison, variation in BCS (within genetic strain and supplementation level) was directly associated with variations in time spent lying (in late lactation). Nevertheless, pasture DMI and time spent in the key behavioral activities were all within the normal expected limits for pasture-fed dairy cows. Thus, thin cows appeared able to achieve their nutritional requirements. Furthermore, even though thinner cows traded-off a small portion of their lying time in late lactation to forage longer, they still rested for normal periods each day. Based on these results, we found no difference in the welfare status of naturally thin and fat cows when they were offered generous pasture allowances with or without concentrate
\end{abstract}

Received August 30, 2011

Accepted January 3, 2012.

${ }^{1}$ Corresponding author: lindsay.matthews1@gmail.com supplementation. The extent to which this pertains under conditions of persistently low feed allowances that result in reductions in BCS remains to be determined.

Key words: body condition, Holstein-Friesian, behavior, welfare

\section{INTRODUCTION}

Current approaches to animal welfare recognize 3 key dimensions within which welfare state can be evaluated: biological function, affective state, and natural living (Fraser, 2003; Matthews, 2008). Biological function and affective state have measurable attributes (Matthews, 2008) and offer opportunities to investigate the effect of farm management on dairy cow welfare and wellbeing, whereas the appropriate quantification of natural living is less clear. Within the biological function dimension, an animal has good welfare when, among other attributes, it grows well, is in good health, reproduces successfully, and is relatively stress free. The concept of affective state acknowledges that animals can have subjective experiences or "feelings" and these are also recognized in frameworks for assessing animal welfare (e.g., freedom from hunger and thirst as one of the Five Freedoms: Farm Animal Welfare Council, 1993).

Both the biological function and affective state dimensions classify adequacy of nutrient intake as a key requirement for protecting wellbeing. For dairy cows, BCS is increasingly viewed as a measure of welfare state (Roche et al., 2009), because it is associated with historical levels of feed intake (McNamara and Hillers, 1986a; Roche et al., 2006) and the incidence of periparturient health disorders (e.g., uterine infection and metabolic disorders: reviewed by Roche et al., 2009). Body condition can also provide a buffer against physical challenges (e.g., cold conditions: Tucker et al., 2007b).

Little published information exists on the adequacy of BCS as a measure of hunger, a key component of the affective state dimension. For concentrate-fed dairy cattle, a negative relationship between BCS and DMI has been reported (Broster and Broster, 1998; Roche et al., 2009). However, BCS is influenced by genetics (Mc- 
Namara and Hillers, 1986a,b; Smith and McNamara, 1990; Roche et al., 2006) and stage of lactation (Roche et al., 2007). Furthermore, increases in DMI may be possible without negatively affecting the time required to undertake other important activities (e.g., resting).

It is unclear, therefore, if the level of BCS (within the typical observed range) is an unambiguous measure of welfare. For example, low BCS may be a reflection of persistent underfeeding or, conversely, a healthy animal with a superior genetic merit for milk production characteristics (Roche et al., 2006, 2009). The usefulness of BCS as a measure of welfare in pasture-fed dairy cattle will be informed by analyses of associations between naturally occurring differences in BCS (i.e., within-herd BCS differences that result from natural variation) and measures of cow welfare (e.g., hunger).

Hunger is a subjective concept and cannot be measured directly. As a result, several behavioral techniques have been used as proxy measures of hunger (see review by D'Eath et al., 2009). Such measures include behavioral recording of time spent searching for, or acquiring, food (e.g., Schütz et al., 2006), rate of food intake (Newman et al., 1994; Sibbald, 1997), or measures of trade-offs between feeding and other important activities (e.g., Matthews and Roberts, 2001).

A study comparing North American (NA) and New Zealand (NZ) Holstein-Friesian (HF) genetic strains with reported differences in BCS profiles (Roche et al., 2006; McCarthy et al., 2007) was used to investigate associations among BCS, pasture DMI, and time spent engaged in DMI-related and resting activities. We hypothesized that thinner cows would graze at an increased rate or spend more time grazing, thereby reducing time available for resting and other important activities. Nutritional treatments were also applied in this study to determine if interactions existed between $\mathrm{BCS}$, diet, and strain during early, mid, and late lactation.

\section{MATERIALS AND METHODS}

This experiment was conducted at Lye Farm, DairyNZ (Hamilton, New Zealand) from July 2002 to June 2004. All procedures were approved by the Ruakura Animal Ethics Committee (Hamilton, New Zealand).

\section{Animals and Treatments}

The experimental design was reported in detail by Roche et al. (2006). Over 2 yr, mixed-age HF cows of NA ( $\mathrm{n}=27$ and 29 in yr 1 and 2 , respectively) and $\mathrm{NZ}$ ( $\mathrm{n}=27$ and 30 cows in yr 1 and 2 , respectively) ancestry were allocated randomly, at calving, to 1 of 3 supplementary feeding treatments in a $2 \times 3$ factorial design. Thirty-two of the cows used in yr 1 and 29 new cows were randomly allocated to treatment at the beginning of yr 2. Cow allocation in both years ensured that treatments were balanced for age $(5.1 \pm 1.60$ and $5.4 \pm 1.68 \mathrm{yr}$ in yr 1 and 2 , respectively), calving date (July $28 \pm 19.9 \mathrm{~d}$ and July $27 \pm 26.0 \mathrm{~d}$ in yr 1 and 2, respectively), and EBV for milk production traits (Harris et al., 1996).

All cows were offered $>45 \mathrm{~kg}$ of DM/cow per day as fresh pasture (calculated to ground level), which was harvested by grazing, and 4 of the 6 treatments ( 2 from each genetic strain) received either 3 or $6 \mathrm{~kg} \mathrm{DM}$ of a pelleted grain-based concentrate per day. The remaining 2 treatments received no concentrate.

\section{Genetic Strains}

The 2 genetic strains were described in detail by Roche et al. (2006). Briefly, the NA strain cows had $>87.5 \%$ NA genetic ancestry and were either imported from the United States or the Netherlands as embryos by Holland Genetics Ltd. for LIC (New Zealand) or were direct descendants of the imported embryos. The mean EBV for the NA cows on study were $+1,270$ (SEM 41.1) $\mathrm{kg}$ of milk, +32 (SEM 1.3) kg of fat, +39 (SEM 1.1) $\mathrm{kg}$ of protein, and +93 (SEM 2.1) $\mathrm{kg}$ of BW. The $\mathrm{NZ}$ cows used in the present experiment were selected from DairyNZ herds based on their breeding worth and the proportion of $\mathrm{NZ}$ ancestry ( $<12.5 \% \mathrm{NA}$ genes). The EBV for the NZ cows on study were +820 (SEM 37.6) $\mathrm{kg}$ of milk, +29 (SEM 1.2) kg of fat, +28 (SEM 1.0) kg of protein, and +52 (SEM 2.6) $\mathrm{kg}$ of BW. Each strain represented 6 to 9 sires, which were common across feeding treatments within strain.

\section{Pasture Management and Supplementary Feeding Treatments}

Cows were grazed rotationally as one herd for the duration of the experiment and only returned to the same area when a minimum of 2 leaves had appeared on the majority $(>75 \%)$ of perennial ryegrass tillers. Cows had access to a fresh allocation of pasture after each milking. Pasture allowance $(>45 \mathrm{~kg}$ of DM/cow per d) was sufficient to ensure unrestricted DMI (up to approximately $25 \mathrm{~kg}$ of $\mathrm{DM} / \mathrm{d}$ ) of fresh pasture in the nonsupplemented cows. Pasture was of high quality throughout both years $(\mathrm{CP}=22.2 \pm 2.73 \% \mathrm{DM}$; OM digestibility $=84.2 \pm 3.87 \% \mathrm{DM} ; \mathrm{NDF}=40.0 \pm 4.38 \%$ $\mathrm{DM} ; \mathrm{ADF}=22.2 \pm 2.50 \% \mathrm{DM}$; lipid $=4.1 \pm 0.25 \%$ $\mathrm{DM} ; \mathrm{NSC}=11.3 \pm 2.50 \% \mathrm{DM} ; \mathrm{ME}=11.8 \pm 0.54$ $\mathrm{MJ} / \mathrm{kg}$ of DM). Quality was maintained throughout the season, despite the high grazing residuals, by strategic mowing. 
Supplement-fed cows received, individually, either 3 or $6 \mathrm{~kg} \mathrm{DM}$ of concentrates $(60 \%$ crushed corn, $32 \%$ crushed barley, $6 \%$ molasses, $2 \%$ wheat middlings; $\mathrm{CP}$ $=11.2 \pm 1.46 \% \mathrm{DM}, \mathrm{NDF}=9.8 \pm 1.99 \% \mathrm{DM}$, lipid $=$ $2.7 \pm 1.22 \% \mathrm{DM}, \mathrm{NSC}=71.9 \pm 2.16 \% \mathrm{DM}$ ) each day as appropriate for the treatments. Concentrate allocation was split into 2 equal feeds and offered during the twice-daily milkings.

\section{Animal Measurements}

$\boldsymbol{B C S}$. Body condition score was determined weekly (on the same day of week and time of day, following an a.m. milking) using a single experienced scorer (JRR). The tactile methodology was used where the cows were loosely restrained in a crush as described by Roche et al. (2004). Such measures of BCS correlate highly with objective measures of body fat (Roche et al., 2009). A 10-point rating scale was used, where 1 is emaciated and 10 is obese (Roche et al., 2004). These scores can be converted to the 5-point scale of Wildman et al. (1982) using the regression equation generated by Roche et al. (2004; 5-point BCS $=1.5+0.32$ 10-point BCS).

Grazing Behavior. Grazing behavior measurements were reported in detail by Sheahan et al. (2011). Times spent grazing, ruminating, lying, and standing were determined by recording each cow's activity at 10-min intervals when the cows were in the paddock (Gary et al., 1970). For logistical reasons, the times spent walking to and from the milking parlor and in the parlor were not recorded; thus, the reported times spent engaged in the various activities do not sum to $24 \mathrm{~h}$. This recording procedure would not have influenced the measures and analyses of time spent grazing or lying as these activities occurred only in the paddock. Further, all treatments had approximately equal opportunities to stand and ruminate in and out of the paddocks. Behaviors were recorded during 2 consecutive 24 -h periods during peak (October), mid (January), and late (April) lactation in each year (approximately 80, 170, and 250 DIM, respectively). This provided $4 \times 24$-h grazing periods at each stage of lactation across $2 \mathrm{yr}$.

Grazing was defined as "cows in the act of eating." When ruminating, the posture (standing or lying) was also recorded. Thus, grazing, standing, and lying were mutually exclusive activities but ruminating was inclusive of portions of time spent lying or standing. For analysis, ruminating was the sum of ruminating standing and ruminating lying. Weather conditions (fine or wet) were also recorded at each scan.

Pasture DMI. Individual cow DMI estimates were obtained at pasture using the $n$-alkane technique outlined by Roche et al. (2008). Briefly, each cow was dosed twice daily (at milking) for a 10-d period with a pellet containing $356 \mathrm{mg}$ of $n$-dotriacontane (C32; i.e., $712 \mathrm{mg}$ of C32/cow per day). Fecal grab samples were collected twice daily from each cow (after milking) during the last $5 \mathrm{~d}$ of the 10 -d period. The 10 fecal samples from each cow for the 5-d period were then bulked, freezedried, and stored at $-17^{\circ} \mathrm{C}$ until alkane analysis. During the same 5-d period, pasture samples were plucked to grazing height on 2 occasions each day, following close observation of the grazing animal, to represent the pasture grazed. A sample of the concentrate offered taken at the morning and afternoon feeding event each day of the 5-d sampling period. The $n$-alkane contents (C25 to C36) of the pasture, supplement, and fecal samples were determined using gas chromatography.

The ratio of pasture C33 (tritriacontane) to dosed C32 (n-dotriacontane) was used to estimate pasture DMI:

Daily pasture DMI $(\mathrm{kg} / \mathrm{cow})=\frac{F_{i} / F_{j} \cdot\left(D_{j}+I_{S} \cdot S_{j}\right)-I_{S} \cdot S_{i}}{P_{i}-\left(P_{j} \cdot F_{i} / F_{j}\right)}$,

where $F_{i}, S_{i}$, and $P_{i}$ are the concentrations $(\mathrm{mg} / \mathrm{kg}$ of $\mathrm{DM}$ ) of the natural odd-chain $n$-alkane (C33) in feces, supplement, and pasture, respectively; $F_{j}, S_{j}$, and $P_{j}$ are the concentrations $(\mathrm{mg} / \mathrm{kg}$ of $\mathrm{DM})$ of the dosed even-chain $n$-alkane (C32) in feces, supplements, and pasture, respectively; and $D_{j}$ and $I_{S}$ are the dose rate $(\mathrm{mg} / \mathrm{d})$ of the even-chain $n$-alkane (C32) and the DMI of the supplement, respectively.

\section{Statistical Analysis}

All analyses were undertaken in GenStat (13th ed., GenStat Committee 2010, VSN International Ltd., Hemel Hempstead, UK). Data were analyzed using REML to combine diet and measurement time information from the between-cow and within-cow strata. The analysis fitted 3 diets, 2 genotypes, 6 measurement times (3 lactation stages by $2 \mathrm{yr}$ ), and their interactions.

The only significant interactions with BCS were with stage of lactation. The regression equations presented for BCS are from the analysis after diet, genotype, measurement time, and their interactions have been fitted. Significant effects for all analyses were declared at $P<0.05$.

\section{RESULTS AND DISCUSSION}

The objective of the current study was to determine the degree of association between naturally occurring variations in BCS and several other potential measures of hunger and welfare status within divergent dairy cow 
Table 1. Mean BCS (1-10 scale; Roche et al., 2004) for cows in each supplementary feeding treatment where 0,3 , or $6 \mathrm{~kg}$ of DM was fed (diet $0,3,6$ ) and of each genetic strain New Zealand (NZ) or North American (NA) Holstein-Friesian (HF) for the 3 stages of lactation in each year of the study

\begin{tabular}{|c|c|c|c|c|c|c|c|c|c|c|}
\hline $\begin{array}{l}\text { Stage of } \\
\text { lactation }\end{array}$ & \multicolumn{3}{|c|}{ Year 1} & $\mathrm{SED}^{1}$ & $P$-value & \multicolumn{3}{|c|}{ Year 2} & $\mathrm{SED}^{1}$ & $P$-value \\
\hline Early & 3.7 & 4.0 & 4.0 & 0.2 & 0.225 & 3.9 & 4.0 & 4.7 & 0.4 & 0.128 \\
\hline \multirow[t]{2}{*}{ Late } & 3.3 & 4.2 & 4.9 & 0.3 & $<0.001$ & 4.3 & 4.1 & 5.3 & 0.3 & $<0.001$ \\
\hline & NZ HF & NA HF & & & & NZ HF & NA HF & & & \\
\hline Mid & 4.5 & 3.8 & & 0.2 & $<0.001$ & 5.2 & 4.3 & & 0.2 & $<0.001$ \\
\hline Late & 4.6 & 3.6 & & 0.2 & $<0.001$ & 5.1 & 4.0 & & 0.3 & $<0.001$ \\
\hline
\end{tabular}

${ }^{1} \mathrm{SED}=$ standard error of the difference.

genetic strains at different stages of lactation. Although all treatments were balanced for BCS at calving, both strain and diet affected BCS at each stage of lactation. The effects of treatment on BCS at each stage of lactation are presented in Table 1. North American cows were thinner $(P<0.001)$, on average, than the NZ HF strain, although the range in BCS within strain was similar (2.5 to 8 and 2.5 to 8.5 for NZ HF and NA $\mathrm{HF}$, respectively). Concentrate supplementation was associated $(P<0.01)$ with higher BCS in mid and late lactation, but not in early lactation. These results are consistent with independent studies comparing these genetic strains (Buckley et al., 2000; Kennedy et al., 2002; Horan et al., 2005; McCarthy et al., 2007; Macdonald et al., 2008).

Detailed milk production and DMI data for this experiment were presented by Roche et al. (2006) and Sheahan et al. (2011). Briefly, NA cows produced greater $(P<0.05)$ yields of milk and milk components than NZ cows, although the milk was more dilute. Concentrate supplementation increased $(P<0.001)$ milk and milk component yield. North American cows consumed more $(P<0.001)$ pasture than NZ cows in mid and late lactation, but not in early lactation, where it was evident that NZ cows reached peak DMI earlier. Concentrate supplementation resulted in a linear increase $(P<0.001)$ in total DMI, but a decline $(P<0.05)$ in pasture DMI at all stages of lactation. All mammals partition stored energy reserves toward lactation postpartum (Roche et al., 2009), suggesting that it is natural for these cows to undergo a period of negative energy balance and for BCS to vary with stage of the lactation cycle. The extent of negative energy balance varies with species (Bauman and Currie, 1980), and within species is, largely, controlled genetically (McNamara and Hillers, 1986b). Some strains of cows, therefore, will be naturally thinner than others (Roche et al., 2006; McCarthy et al., 2007). This is consistent with results presented here, with NA HF dairy cows being thinner than NZ HF cows, despite all being offered the same allowance of pasture and concentrates, and NA HF cows having a greater DMI.

It is generally accepted that animals should be free from hunger and thirst (e.g., Farm Animal Welfare Council, 1993). Hunger is a state that cannot be measured directly in animals, so DMI, rate of DMI, and time spent searching for food may be useful proxies for hunger (D'Eath et al., 2009). The hypothesis investigated in the current experiment was that time spent engaged in foraging and related activities would be negatively correlated with BCS, at the expense of time spent resting. Such a change in behavior might reflect an increase in physiological hunger signals in thinner cows. Over the whole study, the average time spent in each activity per day was $475 \mathrm{~min}$ for grazing, $440 \mathrm{~min}$ for ruminating, $252 \mathrm{~min}$ for standing, and $540 \mathrm{~min}$ for lying. The regression analyses of the behavioral traits and intake measures against BCS showed significant main effects for all behavioral traits measured (percentage of time grazing, ruminating, grazing and ruminating combined, and lying; $P<0.001$ ) except for percentage of time standing $(P=0.79)$. The regressions for DMI $(P<0.001)$ and rate of DMI $(P=0.033)$ were also significant. The interaction between BCS and stage of lactation for the regression analyses was significant for percentage of time ruminating $(P=0.038)$, percentage of time lying $(P=0.028)$, percentage of time standing $(P=0.003)$, DMI $(P=0.004)$, and rate of DMI $(P=$ $0.39)$.

For the 2 variates with significant main effects only (grazing, grazing and rumination combined) the slopes (SE) and intercepts of the regressions were -0.82 (SE 0.25 ) and 20, respectively, for grazing, and -1.63 (SE 0.39 ) and 37, respectively, for grazing and rumination. Thus, the time spent engaged in these activities increased with decreasing BCS at all stages of lactation. 
Table 2. The slopes (SE slope in parentheses) and intercepts of the regression of daily pasture DMI, rate of DMI, and percentage of time spent ruminating, standing, and lying against BCS (1-10 scale; Roche et al., 2004) for early, mid, and late lactation using the data from both years and genetic strains and all diets

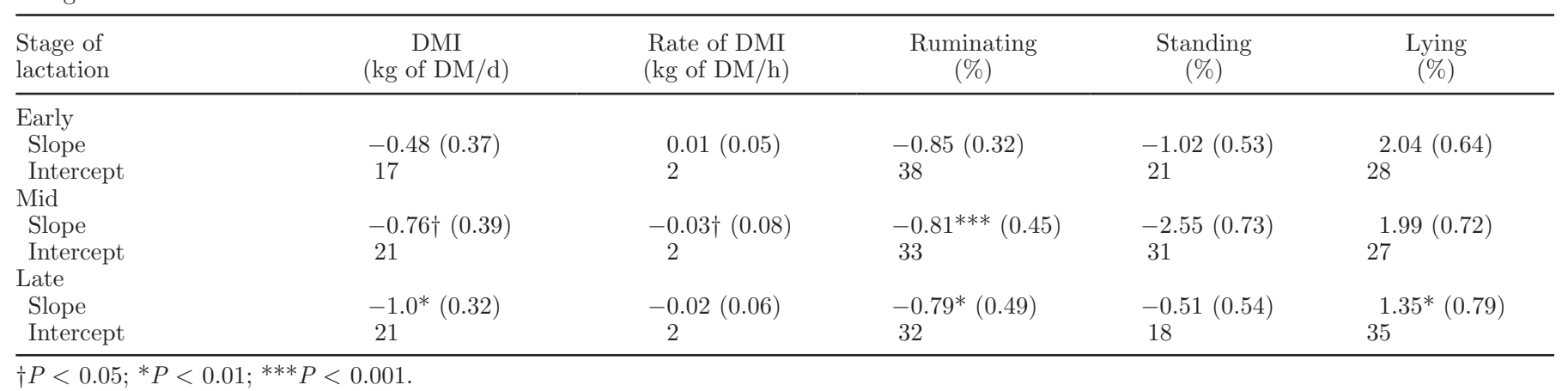

The regression parameters (slope, SE slope, and intercept) for the variates with a significant BCS by stage of lactation interaction are shown in Table 2. Time spent ruminating was negatively associated with BCS in mid $(P<0.001)$ and late lactation $(P<0.01)$, and time spent lying was positively associated $(P<0.01)$ with BCS in late lactation.

Dry matter intake was negatively associated $(P<$ $0.05)$ with BCS during mid and late lactation. These data are consistent with those reported in the reviews by Broster and Broster (1998) and Roche et al. (2009), who also noted an increase in DMI as BCS declined. The aforementioned reviews only considered experiments in which BCS was deliberately manipulated and DMI recorded. In the current study, the associations considered were between natural variation in BCS (within treatment groups) and feeding. The observed trends were similar to those reported where BCS was manipulated, indicating that genetic and environmental effects on BCS have similar effects on hunger and satiety factors. The rate of DMI was negatively associated $(P<0.05)$ with BCS in mid lactation, but the slope was almost flat $(-0.03)$ and unlikely to be biologically meaningful.

Although this study revealed negative associations between time spent grazing and BCS, and between intake and BCS, and a positive association between resting time and BCS, the interpretation of these observations does not necessarily imply an adverse effect on welfare status. First, the DMI and rates of DMI were typical for dairy cattle at pasture (Wales et al., 1999; Thorne et al., 2003; Stockdale, 2004), and we observed no meaningful association between rate of DMI (a proxy for hunger; D'Eath et al., 2009) and BCS. Second, the times spent in all measured behavioral categories were consistent with reported normal behavior under grazing conditions (Wales et al., 1999; Thorne et al., 2003; Stockdale, 2004; Tucker et al., 2007a). Although we observed a decrease in the absolute amount of time spent lying with decreasing BCS in late lactation, and excessive lying deprivation $(<4 \mathrm{~h} / \mathrm{d})$ is known to compromise animal welfare (Fisher et al., 2001; Munksgaard et al., 2005), the proportion of time that cows allocated to lying in the present study was in the range typically reported for healthy dairy cattle at pasture (Tucker et al., 2007a). Furthermore, the percentage of time resting of even the thinner animals (BCS $=3$ ) was $39 \%$ (or 562 min per day, calculated using the regression parameters for late lactation; Table 2) and was within the normal range (Tucker et al., 2007a). Thus, the thinner cows were not sacrificing required resting time to graze. It is worth noting that less time was spent lying across all treatments and animals during inclement weather (data not presented). Less time lying under wet underfoot and ambient conditions have also been reported elsewhere (Schütz et al., 2010). The effect of inclement weather may exaggerate the effects of low BCS on lying times and may, therefore, increase the risk of welfare compromise.

The difference between causality and association must also be considered: the associations between cow BCS and feeding behavior measures may merely reflect a common factor regulating both and not an effect of BCS on feeding behavior or hunger levels per se. For example, cows supplemented with recombinant bST increase both their milk production and DMI; however, growth hormone is a proven lipolytic agent (Bauman and Currie, 1980). Therefore, an increase in DMI and a decrease in BCS in cows would be expected with greater growth hormone concentrations. Consistent with this, cows selected for increased milk production have greater circulating concentrations of growth hormone (Lucy et al., 2009; Grala et al., 2011), lower BCS (Berry et al., 2003; Roche et al., 2006; McCarthy et al., 2007), and greater DMI (Sheahan et al., 2011). If these differences are a result of natural homeorhetic regulation of the somatotropic axis, they cannot necessarily be construed as undermining animal welfare. Consis- 
tent with this premise, Roche et al. (2007) reported no significant association between natural variation in BCS and circulating concentrations of ghrelin pre- and postprandially, suggesting that this physiological signal (Roche et al., 2008) is not indicative of increased hunger in naturally thin cows. The lack of a significant interaction between BCS and supplementary feeding treatment in the current experiment further supports this premise. However, the same argument cannot necessarily be made for cows that are managed into a nonnatural, low-BCS state through persistent underfeeding, and the association with hunger in such situations requires further investigation.

\section{CONCLUSIONS}

Our results indicate that naturally thinner cows within a herd had a greater DMI and spent more time foraging and in related activities than fatter animals. Time spent lying appeared to be traded-off for foraging time in late lactation as the thinner cows spent proportionately less time resting. Nevertheless, pasture DMI and the proportions of time spent in key behavioral activities across the BCS range were within normal limits. Thus, using these measures, and under conditions of generous pasture allowances, with or without concentrate supplementation, we found little evidence to suggest an adverse effect of naturally occurring variations in BCS on hunger-related wellbeing in dairy cows. The extent to which this holds true for conditions with lower feed allowances, or experimentally manipulated BCS, remains to be determined. The effects of combinations of inclement weather and low BCS on welfare also require further study.

\section{ACKNOWLEDGMENTS}

The contributions of the DairyNZ farm and technical staff, and investment from New Zealand dairy farmers through DairyNZ Inc. (Hamilton, New Zealand) and the Ministry of Science and Innovation are gratefully acknowledged.

\section{REFERENCES}

Bauman, D. E., and W. B. Currie. 1980. Partitioning of nutrients during pregnancy and lactation: A review of mechanisms involving homeostasis and homeorhesis. J. Dairy Sci. 63:1514-1529.

Berry, D. P., F. Buckley, P. Dillon, R. D. Evans, M. Rath, and R. F. Veerkamp. 2003. Genetic parameters for body condition score, body weight, milk yield, and fertility estimated using random regression models. J. Dairy Sci. 86:3704-3717.

Broster, W. H., and V. J. Broster. 1998. Body condition score of dairy cows. J. Dairy Res. 65:155-173.

Buckley, F., P. Dillon, M. Rath, and R. F. Veerkamp. 2000. The relationship between genetic merit for yield and live weight, condition score, and energy balance of spring calving Holstein-Friesian dairy cows on grass based systems of milk production. J. Dairy Sci $83: 1878-1886$.

D'Eath, R. B., B. J. Tolkamp, I. Kyriazakis, and A. B. Lawrence. 2009. 'Freedom from hunger' and preventing obesity: The animal welfare implications of reducing food quantity or quality. Anim. Behav. 77:275-288.

Farm Animal Welfare Council. 1993. Second Report on Priorities for Animal Welfare Research and Development. Department for Environment, Food and Rural Affairs Publications, London, UK.

Fisher, A. D., G. A. Verkerk, C. J. Morrow, and L. R. Matthews 2001. The effects of feed restriction and lying deprivation on pituitary-adrenal axis regulation in lactating cows. Livest. Prod. Sci. 73:255-263.

Fraser, D. 2003. Assessing animal welfare at the farm and group level: The interplay of science and values. Anim. Welf. 12:433-443.

Gary, L. A., G. W. Sherritt, and E. B. Hale. 1970. Behavior of Charolais cattle on pasture. J. Anim. Sci. 30:203-206.

Grala, T. M., M. C. Lucy, C. V. C. Phyn, A. J. Sheahan, J. M. Lee, and J. R. Roche. 2011. Somatotropic axis and concentrate supplementation in grazing dairy cows of genetically diverse origin. J. Dairy Sci. 94:303-315.

Harris, B. L., J. M. Clark, and R. G. Jackson. 1996. Across-breed evaluation of dairy cattle. Proc. N.Z. Soc. Anim. Prod. 56:12-15.

Horan, B., P. Dillon, P. Faverdin, L. Delaby, F. Buckley, and M. Rath 2005. The interaction of strain of Holstein-Friesian cows and pasture-based feed systems on milk yield, body weight, and body condition score. J. Dairy Sci. 88:1231-1243.

Kennedy, J., P. Dillon, P. Faverdin, L. Delaby, F. Buckley, and M. Rath. 2002. The influence of cow genetic merit for milk production on response to level of concentrate supplementation in a grass based system. J. Dairy Sci. 75:433-445.

Lucy, M. C., G. A. Verkerk, B. E. Whyte, K. A. Macdonald, L. Burton, R. T. Cursons, J. R. Roche, and C. W. Holmes. 2009. Somatotropic axis components and nutrient partitioning in genetically diverse dairy cows managed under different feed allowances in a pasture system. J. Dairy Sci. 92:526-539.

Macdonald, K. A., G. A. Verkerk, B. S. Thorrold, J. E. Pryce, J. W. Penno, L. R. McNaughton, L. J. Burton, J. A. S. Lancaster, J. H. Williamson, and C. W. Holmes. 2008. A comparison of three strains of Holstein-Friesian grazed on pasture and managed under different feed allowances. J. Dairy Sci. 91:1693-1707.

Matthews, L. R. 2008. Methodologies by which to study and evaluate welfare issues facing livestock systems of production. Aust. J. Exp. Agric. 48:1014-1021.

Matthews, L. R., and N. Roberts. 2001. Quantifying Behavioral Priorities. Supplements to Ethology. R. Apfelback, M. Fendt, S. Kraemer, and B. M. Siemers, ed. Adv. Ethol. 36:214.

McCarthy, S., D. P. Berry, P. Dillon, M. Rath, and B. Horan. 2007. Influence of Holstein-Friesian strain and feed system on bodyweight and body condition score lactation profiles. J. Dairy Sci. 90:1859-1869.

McNamara, J. P., and J. K. Hillers. 1986a. Regulation of bovine adipose tissue metabolism during lactation. 2. Lipolysis response to milk production and energy intake. J. Dairy Sci. 69:3042-3050.

McNamara, J. P., and J. K. Hillers. 1986b. Regulation of bovine adipose tissue metabolism during lactation. 1. Lipid synthesis in response to increased milk production and decreased energy intake. J. Dairy Sci. 69:3032-3041.

Munksgaard, L., M. B. Jensen, L. J. Pedersen, S. W. Hansen, and L. R. Matthews. 2005. Quantifying behavioral priorities-Effects of time constraints on behavior of dairy cows (Bos taurus). Appl. Anim. Behav. Sci. 92:3-14

Newman, J. A., P. D. Penning, A. J. Parsons, A. Harvey, and R. J. Orr. 1994. Fasting affects intake behaviour and diet preference of grazing sheep. Anim. Behav. 47:185-193.

Roche, J. R., D. P. Berry, and E. S. Kolver. 2006. Holstein-Friesian strain and feed effects on milk production, body weight, and body condition score profiles in grazing dairy cows. J. Dairy Sci. 89:3532-3543.

Roche, J. R., D. P. Berry, J. M. Lee, K. A. Macdonald, and R. C. Boston. 2007. Describing the body condition score change between 
successive calvings: A novel strategy generalizable to diverse cohorts. J. Dairy Sci. 90:4378-4396.

Roche, J. R., D. Blache, J. K. Kay, D. R. Miller, A. J. Sheahan, and D. W. Miller. 2008. Neuroendocrine and physiological regulation of intake, with particular reference to domesticated ruminant animals. Nutr. Res. Rev. 21:207-234.

Roche, J. R., P. G. Dillon, C. R. Stockdale, L. H. Baumgard, and M. J. VanBaale. 2004. Relationships among international body condition scoring systems. J. Dairy Sci. 87:3076-3079.

Roche, J. R., N. C. Friggens, J. K. Kay, M. W. Fisher, K. J. Stafford, and D. P. Berry. 2009. Invited review: Body condition score and its association with dairy cow productivity, health and welfare. J. Dairy Sci. 92:5769-5801.

Schütz, K., D. Davison, and L. R. Matthews. 2006. Do different levels of moderate feed deprivation in dairy cows affect feeding motivation? Appl. Anim. Behav. Sci. 101:253-263.

Schütz, K. E., K. V. Clark, N. R. Cox, L. R. Matthews, and C. B. Tucker. 2010. Responses to short-term exposure to simulated rain and wind by dairy cattle: Time budgets, shelter use, body temperature and feed intake. Anim. Welf. 19:375-383.

Sheahan, A. J., E. S. Kolver, and J. R. Roche. 2011. Genetic strain and side effects on grazing behavior, pasture intake, and milk production. J. Dairy Sci. 94:3583-3591.

Sibbald, A. M. 1997. The effect of body condition on the feeding behaviour of sheep with different times of access to food. Anim. Sci. 64:239-246.
Smith, T. R., and J. P. McNamara. 1990. Regulation of bovine adipose tissue metabolism during lactation. 6. Cellularity and hormonesensitive lipase activity as affected by genetic merit and energy intake. J. Dairy Sci. 73:772-783.

Stockdale, C. R. 2004. Effects of level of feeding of concentrates during early lactation on the yield and composition of milk from grazing dairy cows with varying body condition score at calving. Aust. J. Exp. Agric. 44:1-9.

Thorne, P. L., J. J. Jago, E. S. Kolver, and J. R. Roche. 2003. Diet and genotype affect behavior of Holstein-Friesian dairy cows during late lactation. Proc. N.Z. Soc. Anim. Prod. 63:124-127.

Tucker, C. B., D. E. Dalley, J.-L. K. Burke, and D. A. Clark. 2007a. Milking cows once daily influences behavior and udder firmness at peak and mid lactation. J. Dairy Sci. 90:1692-1703.

Tucker, C. B., A. Rogers, G. A. Verkerk, P. E. Kendall, J. R. Webster, and L. R. Matthews. 2007b. Effects of shelter and body condition on the behavior and physiology of dairy cattle in winter. Appl. Anim. Behav. Sci. 105:1-13.

Wales, W. J., P. T. Doyle, C. R. Stockdale, and D. W. Dellow. 1999. Effects of variations in herbage mass, allowance, and level of supplement on nutrient intake and milk production of dairy cows in spring and summer. Aust. J. Exp. Agric. 39:119-130.

Wildman, E. E., G. M. Jones, P. E. Wagner, R. L. Boman, H. F. Troutt Jr., and T. N. Lesch. 1982. A dairy cow body condition scoring system and its relationship to selected production characteristics. J. Dairy Sci. 65:495-501. 